\title{
Campylobacter lari
}

National Cancer Institute

\section{Source}

National Cancer Institute. Campylobacter lari. NCI Thesaurus. Code C86236.

A species of microaerophilic, Gram-negative, curved or spiral bacilli assigned to the phylum Proteobacteria. This species is motile using a single flagellum at each pole, nonspore forming, oxidase positive, catalase positive, reduces nitrate, produces hydrogen sulfide, and does not hydrolyze hippurate nor ferment glucose. C. lari is associated in recurrent gastroenteritis in children, causes septicemia and enteritis in immunodeficient patients and is commensal in healthy seagulls, birds, mussels and oysters. 